\title{
OS ÓRGÃOS DE CONTROLE E A PRESTAÇÃO DE CONTAS ANUAIS NOS INSTITUTOS FEDERAIS DE EDUCAÇÃO, CIÊNCIA E TECNOLOGIA COMO MEIO PARA MELHORIA DO PROCESSO DE ENSINO-APRENDIZAGEM
}

\author{
Alessandro Franco de Melo*, Georges Souto Rocha \\ E-mail*: alessandromelo@hotmail.com \\ Universidade Federal da Bahia; Instituto Federal de Educação Ciência e Tecnologia da Bahia
}

DOI: $10.15628 /$ rbept.2020.9676

Artigo submetido em: mar/2020 e aceito em: mar/2020

\begin{abstract}
RESUMO
A prestação de contas parte da obrigação social e pública de prestar informações sobre algo pelo qual a Administração Pública é responsável, sendo esse conceito base da transparência e do controle social. Dentro desse contexto, os Institutos Federais de Educação, Ciência e Tecnologia - IF's, por não fugirem a regra, apresentam-se como unidades prestadoras de contas que se submetem aos órgãos de controle interno e externo. Por meio de uma pesquisa exploratória, através dos procedimentos bibliográfico e documental para a coleta de informações, o presente artigo visa demonstrar como ocorre a prestação de contas anuais dos IF's e suas contribuições na melhoria do processo de ensino-aprendizagem na Educação Profissional e Tecnológica - EPT à medida que se busca um funcionamento mais efetivo das Instituições.
\end{abstract}

Palavras-Chave: Prestação de contas. Educação Profissional e Tecnológica. Controle interno e externo. Processo de ensino-aprendizagem.

\section{THE CONTROL BODIES AND THE ANNUAL ACCOUNTABILITY IN THE FEDERAL INSTITUTES OF EDUCATION, SCIENCE AND TECHNOLOGY AS A MEANS FOR IMPROVING THE TEACHING-LEARNING PROCESS}

\begin{abstract}
The accountability starts from the social and public obligation to provide information about something for which the Public Administration is responsible, this concept being the basis of transparency and social control. Within this context, the Federal Institutes of Education, Science and Technology - IF's, for not breaking the rule, present themselves as accountable units that submit to internal and external control bodies. Through an exploratory research, through bibliographic and documentary procedures for the collection of information, this article aims to demonstrate how the IF's annual accountability and their contributions in improving the teaching-learning process in Professional and Technological Education - EFA as the Institutions are sought to function more effectively.
\end{abstract}

Keywords: Accountability. Professional and Technological Education. Internal and external control. Teaching-learning process. 


\section{INTRODUÇÃO}

A Rede Federal de Educação Profissional, Científica e Tecnológica RFEPCT, criada pela Lei no 11.892, de 29 de dezembro de 2008, constituiu um marco na ampliação, interiorização e diversificação da educação profissional e tecnológica no país.

Em 2019, a Rede Federal está composta por 38 Institutos Federais de Educação, Ciência e Tecnologia - IF's, 02 Centros Federais de Educação Tecnológica (Cefet), a Universidade Tecnológica Federal do Paraná (UTFPR), 23 escolas técnicas vinculadas às universidades federais e o Colégio Pedro II. Considerando os respectivos campi associados a estas instituições federais, têm-se ao todo 659 unidades distribuídas entre as 27 unidades federadas do país ${ }^{1}$.

Em 2018, toda a RFEPCT apresentou um gasto direto total de $\mathrm{R} \$$ 16.383.014.837, $00^{2}$, envolvendo os gastos com pessoal, investimentos e custeios dos Institutos Federais, dos Centros Federais de Educação Tecnológica - CEFET's e o Colégio Pedro II, sendo legítimo que os cidadãos questionem: como têm sido empregado os investimentos destinados à educação, mais especificamente, na Educação Profissional, Científica e Tecnológica?

A legitimidade deste interesse dos cidadãos baseia-se no conceito da teoria da agência apresentada por Jensen \& Meckling (2008), os quais iniciaram a discussão acerca desta teoria discorrendo sobre os problemas de agência que surgem quando o principal transfere o poder de decisão para uma segunda parte (agente), que deverá exercer a gestão dos recursos e atuar no melhor interesse do principal, o que gera uma obrigação de prestação de contas da segunda parte perante a primeira, pois nem sempre 0 agente irá agir de acordo com o interesse do principal.

No âmbito da Administração Pública, observa-se no texto de Silva e Mário (2014) que a teoria da agência ocorre entre cidadãos e o governo, na qual os cidadãos (principal) delegam um poder de decisão aos gestores públicos (agentes) que exercem a gestão dos recursos advindos do principal, havendo, como foi dito, obrigação de prestação de contas por parte dos gestores públicos.

Sendo assim, partindo-se do pressuposto de que há racionalidade limitada e possibilidade de desvio de finalidade nas ações dos agentes, conforme ressalva Buta, Teixeira e Schurgelies (2018, p. 49), a relação principal e agente incorre em custos de monitoramento voltados à limitação de

\footnotetext{
1 Dados obtidos no site do Ministério da Educação (http://portal.mec.gov.br/rede-federalinicial/).

2 Dados obtidos na Plataforma Nilo Peçanha (https://www.plataformanilopecanha.org/).

Vol. 2 (2020) 
atividades irregulares do agente, traduzidos em preocupação constante com o controle do exercício do poder.

O presente artigo visa demonstrar como ocorre a prestação de contas anuais dos IF's e a atuação dos respectivos órgãos de controle interno e externo nessa atividade, buscando esclarecer a forma, os trâmites, os responsáveis e as principais peças e documentos necessários para elaboração dessa importante atividade que impacta, consequentemente, no processo de ensino-aprendizagem.

Nesse cenário, justifica-se a relevância deste estudo dada as contribuições da prestação de contas na melhoria do processo de ensinoaprendizagem na Rede Federal de Educação Profissional, Científica e Tecnológica à medida que garante as condições de funcionamento das Instituições e promove uma gestão mais democrática e transparente quanto ao atingimento de suas finalidades.

$\mathrm{Na}$ elaboração deste artigo, adotou-se a metodologia de revisão bibliográfica por meio de uma pesquisa exploratória, através dos procedimentos bibliográfico e documental para a coleta de informações que foram realizadas na doutrina especializada e nos normativos correlatos vigentes.

\section{CONCEITOS DE CONTROLE E PRESTAÇÃO DE CONTAS NO SETOR PÚBLICO}

Trazendo aqui a ideia de controle para o setor público, Meirelles (2009, p. 671) afirma que controle "é a faculdade de vigilância, orientação e correção que um Poder, órgão ou autoridade exerce sobre a conduta funcional de outro". Di Pietro (2014, p. 809), na mesma esteira, ressalta que seria "o controle da Administração Pública como o poder de fiscalização e correção que sobre ela exercem os órgãos do Poder Judiciário, Legislativo e Executivo".

O controle na administração pública apresenta, frequentemente, duas dimensões didáticas: a dimensão vertical, que aborda o controle dos gestores públicos pelos cidadãos/eleitores; e a dimensão horizontal, que está relacionada a uma rede de órgãos com competência para questionar e punir os agentes públicos pelo cumprimento irregular de suas responsabilidades. Em democracias representativas consolidadas, como o caso do Brasil, o controle opera tanto em sentido vertical bem como em sentido horizontal.

Levando em conta essa preocupação constante com o controle do exercício do poder, o parágrafo único do artigo 70 da Constituição da República Federativa do Brasil - CRFB apresenta quem são os responsáveis pela prestação de contas: 
dinheiros, bens e valores públicos ou pelos quais a União responda, ou que, em nome desta, assuma obrigações de natureza pecuniária.

$\mathrm{Na}$ área pública, segundo Castro (2009, p. 304), a existência de um órgão/entidade (como uma escola, instituto ou universidade) e a utilização de recursos públicos para executar uma despesa orçamentária exige uma prestação de contas com um nível mais detalhado de informação, capaz de poder avaliar se os objetivos descritos foram atingidos.

Assim, a prestação de contas, que inicialmente virou sinônimo de elaboração de balanços, centrando-se apenas nos aspectos financeiros e patrimoniais, passa a ser um conceito mais amplo do que o tradicional, ou seja, não é apenas a exposição de resultados quanto a custos, receitas e despesas contábeis, nem somente a demonstração do desempenho quantitativo, mas inclui aspectos qualitativos e visa envolver todos os grupos de interesses da organização, conforme Schwart apud Andrade (2011, p. 11), estes citados por Aragão Júnior (2018, p.59).

Tal ampliação do conceito de prestação de contas advém da ideia de accountability, termo da língua inglesa que não possui tradução específica na língua pátria, mas que remete à ideia de prestação de contas, transparência ou responsabilização dos gestores quanto à execução e administração dos recursos públicos, a fim de assegurar uma administração responsável.

A accountability, portanto, deve ser entendida como uma filosofia de prestação de contas: significa a responsabilidade de se prestar contas ao cidadão das ações desenvolvidas e dos resultados alcançados, onde deve haver uma preocupação em falar a linguagem do cidadão, pois parte da ideia de uma gestão democrática (CASTRO, 2009).

Hodiernamente, a função do instituto da prestação de contas parte da obrigação social e pública de prestar informações sobre algo pelo qual a Administração Pública é responsável, sendo esse conceito relacionado a transparência e controle social.

\section{CONTROLE INTERNO E EXTERNO DO PODER EXECUTIVO FEDERAL}

O controle da administração pública é a atividade de verificação e exame, pela própria Administração ou por outros Poderes, da efetiva correção na conduta gerencial de um Poder, órgão ou autoridade, com o escopo de garantir atuação conforme aos ditames legais e ao que foi pactuado. 
Quanto aos órgãos de controle que atuam frente aos IF's, observam-se órgãos ligados ao controle interno e ao controle externo, a luz do caput do artigo 70 da CRFB, a saber:

\begin{abstract}
A fiscalização contábil, financeira, orçamentária, operacional e patrimonial da União e das entidades da administração direta e indireta, quanto à legalidade, legitimidade, economicidade, aplicação das subvenções e renúncia de receitas, será exercida pelo Congresso Nacional, mediante controle externo, e pelo sistema de controle interno de cada Poder. (grifo nosso).
\end{abstract}

Assim, resta claro que os órgãos de controle interno fazem parte do sistema de controle interno do Poder Executivo Federal. Já o controle externo é exercido pelo Congresso Nacional, ou seja, pelo Poder Legislativo Federal, por meio do Tribunal de Contas da União - TCU, conforme será apresentado.

\title{
3.1 SISTEMA DE CONTROLE INTERNO DO PODER EXECUTIVO FEDERAL
}

O controle interno é aquele exercido por cada um dos Poderes sobre seus próprios atos e agentes, ou seja, o poder de fiscalizar e de rever os atos ocorre dentro da mesma estrutura de Poder. (DI PIETRO, 2010).

A CRFB apresenta brevemente o sistema de controle interno, em seu artigo 74. O Decreto oㅜ 3.591, de 06 de setembro de 2000, detalha esse sistema de controle interno apresentando seus integrantes, sendo destacados aqui os seguintes órgãos/unidades:

Art. 80 Integram o Sistema de Controle Interno do Poder Executivo Federal:

I - a Controladoria-Geral da União, como Órgão Central, incumbido da orientação normativa e da supervisão técnica dos órgãos que compõem o Sistema;

[...]

Art. 14. As entidades da Administração Pública Federal indireta deverão organizar a respectiva unidade de auditoria interna, com o suporte necessário de recursos humanos e materiais, com o objetivo de fortalecer a gestão e racionalizar as ações de controle. (grifos nossos) 
Dessa forma, serão explicitados adiante os papéis da ControladoriaGeral da União - CGU e das unidades de Auditoria Interna - AUDIN's na respectiva prestação de contas anuais dos Institutos Federais.

\subsection{CONTROLE EXTERNO: O TRIBUNAL DE CONTAS DA UNIÃO - TCU}

O Tribunal de Contas da União - TCU é um órgão autônomo, que auxilia o Congresso Nacional (Poder Legislativo) a exercer o controle externo, fiscalizando os gastos dos Poderes Executivo, Judiciário e do próprio Legislativo. Ressalve-se que, apesar de ser um tribunal, o Tribunal de Contas não faz parte do Poder Judiciário.

Mais especificamente às atribuições ligadas às atividades de prestação de contas que exerce sobre os Institutos Federais, extraem-se do artigo 71 da CRFB as seguintes competências do TCU:

II - julgar as contas dos administradores e demais responsáveis por dinheiros, bens e valores públicos da administração direta e indireta, incluídas as fundações e sociedades instituídas e mantidas pelo Poder Público federal, e as contas daqueles que derem causa a perda, extravio ou outra irregularidade de que resulte prejuízo ao erário;[...]

VIII - aplicar aos responsáveis, em caso de ilegalidade de despesa ou irregularidade de contas, as sanções previstas em lei, que estabelecerá, entre outras cominações, multa proporcional ao dano causado ao erário;[...]

IX - assinar prazo para que o órgão ou entidade adote as providências necessárias ao exato cumprimento da lei, se verificada ilegalidade; [...] (grifos nossos).

Sua composição é definida no artigo 73 da Carta Magna, sendo integrado por 9 (nove) Ministros com jurisdição em todo o território nacional, que serão escolhidos um terço pelo Presidente da República e dois terços pelo Congresso Nacional.

Ressalta-se que a prestação de contas, no seu sentido mais amplo trazido pela ideia de accountability, quando aplicado ao controle externo, tornase um marco teórico fundamental para a determinação de qual aspecto da gestão será examinado e cobrado dos administradores públicos: a legalidade, a economicidade, a eficiência, a eficácia e a efetividade, sendo esta uma importante ferramenta para instrumentalizar o próprio controle a ser executado. 
Apresentados os órgãos de controle interno e externo, demonstrar-seá, adiante, como ocorre a prestação de contas anuais dos IF's e a atuação dos respectivos órgãos de controle interno e externo nessa atividade.

\section{PRESTAÇÃO DE CONTAS ANUAIS}

O processo de exame e julgamento de prestação de contas anuais é expressão máxima do poder controlador do TCU, dado que, contrariamente aos sistemas de controladoria adotados em outros países, permite ao Tribunal exercer juízo sobre a gestão dos responsáveis pela administração de recursos públicos federais, bem como fazer determinações e imputar sanções, as quais, no que tange ao mérito, não são recorríveis a outro órgão que não ao próprio TCU, o que the confere independência, conforme se infere dos ensinamentos de Castro (2009).

Desde 2010, o TCU deixou de julgar todas as contas apresentadas e passou a selecionar processos com base na materialidade, relevância e risco, haja vista a revogação da Instrução Normativa TCU no 57, de 27 de agosto de 2008, pela vigente Instrução Normativa TCU no 63, de 01 de setembro de 2010, que estabelece normas de organização e de apresentação dos relatórios de gestão e das peças complementares que constituirão os processos de contas.

Também há duas decisões normativas do TCU sobre a matéria editadas para cada exercício financeiro, as quais serão citadas adiante. Uma vai estabelecer regras para a apresentação das contas pelos administradores, especialmente, para a elaboração do relatório de gestão; outra determina as unidades prestadoras de contas cujos responsáveis terão as contas julgadas pelo Tribunal e estabelece as regras para as instâncias que atuarão na análise das contas para o julgamento.

Assim, o processo de contas anuais compreende três etapas complementares: a prestação de contas, a auditoria nas contas e o julgamento das contas dos administradores. Cada uma dessas etapas é realizada por agente e órgãos distintos, responsáveis pela entrega dos produtos específicos, conforme detalhado na Figura 1 a seguir:

Figura 01: quadro sobre etapas do processo de contas anuais.

\begin{tabular}{|c|c|c|}
\hline ETAPAS & RESPONSÁVEL & PRODUTOS \\
\hline 1ª) Prestação de contas & Administração & + Relatório de Gestão \\
\hline $\left.2^{a}\right)$ Auditoria anual de contas & $\begin{array}{l}\text { Órgão de controle } \\
\text { interno }\end{array}$ & $\begin{array}{l}\text { + Relatório de auditoria de } \\
\text { gestão } \\
\text { + Certificado de auditoria } \\
\text { + Parecer do dirigente do órgão } \\
\text { de controle interno }\end{array}$ \\
\hline
\end{tabular}


Fonte: elaborado pelo autor.

Didaticamente, para efeitos de apresentação deste artigo, essas etapas serão divididas em duas fases distintas na prestação de contas pelos Institutos Federais: a primeira fase trata da elaboração obrigatória anual do relatório de gestão (englobando apenas a primeira etapa do quadro anterior); já a segunda fase, trata do processo de julgamento das contas (englobando a segunda e terceira etapas do quadro anterior).

\subsection{PRIMEIRA FASE: O RELATÓRIO DE GESTÃO}

O relatório de gestão é o documento elaborado pelo gestor de órgão/entidade para demonstrar, esclarecer e justificar os resultados alcançados frente aos objetivos estabelecidos em um determinado exercício. Ou seja, sua função básica é a prestação de contas.

Segundo o inciso II do parágrafo único do artigo 1ำ da Instrução Normativa TCU nำ 63, de 01 de setembro de 2010, considera-se como relatório de gestão:

[...] documentos, informações e demonstrativos de natureza contábil, financeira, orçamentária, operacional ou patrimonial, organizado para permitir a visão sistêmica do desempenho e da conformidade da gestão dos responsáveis por uma ou mais unidades jurisdicionadas durante um exercício financeiro;[...]

Conforme o artigo $3^{\circ}$ do citado normativo, "os relatórios de gestão devem ser apresentados anualmente ao Tribunal pelos responsáveis pelas unidades jurisdicionadas, relacionadas em decisão normativa, que lhes fixará a forma, conteúdo e prazo.".

Uma das decisões normativas emitida pelo TCU neste sentido é a Decisão Normativa TCU no 170, de 19 de setembro de 2018, dispondo acerca das unidades cujos dirigentes máximos devem prestar contas de suas gestões ocorridas no exercício de 2018, devendo ser observada na elaboração dos relatórios de gestão do ano corrente por todos os Institutos Federais.

Determina a referida decisão normativa em seu artigo $3^{\circ}$ que o relatório de gestão deve informar, no mínimo: os objetivos e as metas definidos para o exercício; os resultados alcançados ao fim do exercício, demonstrando como 
a estratégia, a governança e a alocação de recursos contribuíram para o alcance dos resultados; e as justificativas para objetivos ou metas não atingidos.

Quanto aos responsáveis pela gestão, o artigo 6으 da citada Decisão Normativa inclui em seu rol os titulares e seus substitutos que desempenharem, durante o período a que se referirem as contas, as seguintes naturezas de responsabilidade, ligadas a Unidade Prestadora de Contas - UPC:

\begin{abstract}
I - dirigente máximo da UPC;
II - membro de diretoria ou ocupante de cargo de direção no nível de hierarquia imediatamente inferior e sucessivo ao do dirigente de que trata 0 inciso anterior, com base na estrutura de cargos aprovada para a UPC;

III. membro de órgão colegiado que, por definição legal, regimental ou estatutária, seja responsável por ato de gestão que possa afetar o alcance de objetivos ou causar impacto na economicidade, eficiência, eficácia da gestão da UPC.
\end{abstract}

Traduzindo para a realidade dos Institutos Federais (uma UPC), temos como responsável citado no inciso I a figura do Reitor; no inciso II, os PróReitores, Diretores Sistêmicos e Diretores-Gerais de Campi; e no inciso III, os membros do Conselho Superior - CONSUP.

Referente a estes últimos, ressalta-se o parágrafo terceiro do artigo em tela, o qual dispensa de informar estes membros do CONSUP no rol de responsáveis do sistema informatizado do TCU para prestação de contas (Sistema e-Contas), porém com a ressalva dos Institutos manterem e disponibilizarem, quando solicitados pelos órgãos de controle, cadastro informatizado com determinadas informações.

Por oportuno, cite-se o papel do CONSUP dos Institutos Federais, o qual deve apreciar as contas do exercício financeiro e o relatório de gestão anual, emitindo parecer conclusivo sobre a propriedade e regularidade dos registros, estando este parecer contido na estrutura de conteúdos gerais dos relatórios de gestão, conforme se observa no anexo único da Portaria TCU nํㅜ 369, de 17 de dezembro de 2018.

Outro parecer também citado nesta portaria, integrante da estrutura de conteúdos gerais dos relatórios de gestão, é o parecer da unidade de auditoria interna - AUDIN. Sobre o papel das AUDIN's dos Institutos Federais quanto ao respectivo relatório de gestão, o parágrafo sexto do artigo 15 do Decreto oㅡ 3.591 , de 06 de setembro de 2000 , afirma que "A auditoria interna examinará 
e emitirá parecer sobre a prestação de contas anual da entidade e tomadas de contas especiais."

Este parecer vem sendo exigido como elemento importante para conferir confiabilidade às informações apresentadas nas contas e no relatório de gestão, trazendo informações sobre controles internos, irregularidades apuradas, regularidade das informações contábeis e ainda informações sobre o Plano Anual de Auditoria Interna (PAINT).

O relatório de gestão deve ser apresentado até a data que é fixada pela decisão normativa vigente, exclusivamente por intermédio do Sistema eContas, podendo haver prorrogação deste prazo pelo Plenário do Tribunal, em caráter excepcional, mediante o envio de solicitação fundamentada formulada, nos caso dos IF's, pelo Ministro da Educação, tudo conforme o artigo 14 da Decisão Normativa TCU no 170, de 19 de setembro de 2018, e os artigos $7^{\circ}$ e 8o da Instrução Normativa TCU nํ63, de 01 de setembro de 2010.

Ocorrendo descumprimento dos prazos, o TCU pode julgar as contas como irregulares por omissão no dever de prestar contas, além de cominar multa, consoante previsto na alínea "a" do inciso III do artigo 16 e no inciso II do artigo 58 da Lei no 8.443, de 16 de julho 1992 (que dispõe sobre a Lei Orgânica do Tribunal de Contas da União e dá outras providências).

A publicação do relatório de gestão, importante ação de transparência aos cidadãos, deverá ocorrer no portal do TCU em até 45 (quarenta e cinco) dias da data-limite para a entrega especificada pela decisão normativa vigente, consideradas as prorrogações previstas, e no site do respectivo Instituto Federal em até 30 dias, contados da publicação do relatório de gestão pelo TCU (arts. 20 a 23 da Decisão Normativa TCU ํำ170, de 19 de setembro de 2018).

\subsection{SEGUNDA FASE: O PROCESSO DE JULGAMENTO DAS CONTAS}

O processo de contas, conforme o inciso II do parágrafo único do artigo 1ำ da Instrução Normativa TCU no 63, de 01 de setembro de 2010 é o

Processo de trabalho do controle externo destinado a avaliar e julgar o desempenho e a conformidade da gestão das pessoas abrangidas pelos incisos I, III, IV, V e VI do art. 5ํㅡㄹ da Lei 8.443/1992, com base em documentos, informações e demonstrativos de natureza contábil, financeira, orçamentária, operacional ou patrimonial, obtidos direta ou indiretamente. 
Assim, entre as pessoas abrangidas pelo inciso I do artigo $5^{\circ}$ da Lei $n^{\circ}$ 8.443, de 16 de julho 1992, encontram-se os Institutos Federais, objeto do presente estudo.

Conforme o artigo 4ำ da Instrução Normativa TCU no 63, de 01 de setembro de 2010,

O Tribunal definirá anualmente, em decisão normativa, as unidades jurisdicionadas cujos responsáveis terão processos de contas ordinárias constituídos para julgamento, assim como os conteúdos e a forma das peças que os comporão e os prazos de apresentação.

Uma das decisões normativas emitida pelo TCU neste sentido é a Decisão Normativa TCU no 172, de 12 de dezembro de 2018, dispondo sobre a relação das unidades prestadoras de contas (incluem-se, aqui, os IF's) cujos responsáveis terão as contas de 2018 julgadas pelo Tribunal e especifica a forma, os prazos e os conteúdos para a elaboração das peças de responsabilidade dos órgãos de controle interno e das instâncias supervisoras que comporão os processos de contas.

Rememore-se, aqui, que o TCU deixou de julgar todas as contas apresentadas pelos órgãos e entidades, passando a selecionar processos com base na materialidade, relevância e risco, a partir da vigência da Instrução Normativa TCU no 63, de 01 de setembro de 2010.

Inicialmente, as informações, peças e responsáveis que constituíram os autos iniciais dos processos de contas dizem respeito, exatamente, as informações contidas na primeira fase da prestação de contas anual, ou seja, o relatório de gestão.

Dando continuidade a esse rol de informações e documentos que comporão o processo de contas, segundo o artigo $3^{\circ}$ da Decisão Normativa TCU no 172, de 12 de dezembro de 2018 e o artigo 13 da Instrução Normativa TCU no 63, de 01 de setembro de 2010, observa-se, daqui em diante, a participação de dois agentes externos aos IF's: primeiramente o órgão central do sistema de controle interno do Poder Executivo Federal - a CGU, por meio da emissão de três peças, sendo estas o relatório de auditoria de gestão, o certificado de auditoria e o parecer conclusivo do seu dirigente; e seguidamente o Ministério da Educação, por meio do pronunciamento ministerial.

Consoante os parágrafos $1^{\circ}$ e $2^{\circ}$ do artigo $3^{\circ}$ da Decisão Normativa TCU no 172 , de 12 de dezembro de 2018, respectivamente, o relatório de auditoria é o documento que apresenta informações e conclusões da auditoria realizada nas contas pelo órgão de controle interno, abrangendo métodos, evidências e fundamentação para as constatações apontadas, de forma suficiente para subsidiar o julgamento das contas. 
Já o certificado de auditoria, seria o documento que formaliza a opinião quanto à regularidade da gestão, devendo estar fundamentada em evidências suficientes e adequadas descritas no relatório de auditoria.

O parecer conclusivo do dirigente da CGU consignará "qualquer irregularidade ou ilegalidade constatada, indicando as medidas adotadas para corrigir as faltas encontradas", segundo descreve o inciso III, artigo $9^{\circ}$ da Lei ㄲo 8.443, de 16 de julho 1992, encaminhado, logo em seguida, o processo de contas ao ministro de estado supervisor, que no caso dos Institutos Federais se refere ao Ministro da Educação.

Seguindo seu curso, o processo é encaminhado para pronunciamento expresso do Ministro da Educação, devendo este atestar haver tomado conhecimento das conclusões contidas no parecer do dirigente da CGU sobre o desempenho e a conformidade da gestão do Instituto Federal supervisionado.

As peças de responsabilidade da CGU devem ser apresentadas até a data que é fixada pela decisão normativa vigente, exclusivamente por intermédio do Sistema e-Contas, tendo o Ministro da Educação o prazo sucessivo de 15 dias.

Pode haver prorrogação deste prazo pelo Plenário do TCU, em caráter excepcional, mediante o envio de solicitação fundamentada formulada pela CGU ou pelo Ministro da Educação, tudo conforme o artigo $7^{\circ}$ da DN TCU $n^{\circ}$ 172/2018 e os artigos $7^{\circ}$ e $8^{\circ}$ da IN TCU no 63/2010.

Ocorrendo descumprimento dos prazos, o TCU pode vir a considerar como grave infração à norma regulamentar, além de cominar, conforme o disposto no inciso II do art. 58 da Lei no 8.443 , de 16 de julho 1992 e o inciso II do artigo 8ㅇ da Instrução Normativa TCU ํㅡ 63, de 01 de setembro de 2010.

Os relatórios de gestão dos IF's serão publicados no Portal do TCU na internet após a conclusão dos trabalhos da CGU.

\subsubsection{Resultados do julgamento do TCU}

Nesse momento há o julgamento propriamente dito pelo TCU quanto às contas dos Institutos Federais, no qual o Tribunal realiza sua instrução técnica e emite sua decisão.

Com base na Lei oㅜ 8.443, de 16 de julho 1992, as contas apresentadas pelos órgãos/entidades podem ser julgadas como: regulares; regulares com ressalva; ou irregulares.

As contas serão julgadas como "regulares" quando expressarem, de forma clara e objetiva, a exatidão dos demonstrativos contábeis, a legalidade, 
a legitimidade e a economicidade dos atos de gestão do responsável, dando o TCU quitação plena ao gestor responsável.

Já as contas serão julgadas "regulares com ressalva" quando evidenciarem impropriedade ou qualquer outra falta de natureza formal de que não resulte dano ao erário. Quando julgar as contas regulares com ressalva, o Tribunal dará quitação ao gestor responsável e lhe determinará, ou a quem Ihe haja sucedido, a adoção de medidas necessárias à correção das impropriedades ou faltas identificadas, de modo a prevenir a ocorrência de outras semelhantes.

O julgamento das contas como irregulares ocorre quando comprovada qualquer das seguintes ocorrências, segundo o inciso III do artigo 16 da Lei no 8.443, de 16 de julho 1992:
a) omissão no dever de prestar contas;
b) prática de ato de gestão ilegal, ilegítimo, antieconômico, ou infração à norma legal ou regulamentar de natureza contábil, financeira, orçamentária, operacional ou patrimonial;
c) dano ao Erário decorrente de ato de gestão ilegítimo ao antieconômico;
d) desfalque ou desvio de dinheiros, bens ou valores públicos.

Quando o TCU julgar as contas irregulares, havendo débito, o Tribunal condenará o responsável ao pagamento da dívida, podendo, ainda, aplicar-Ihe multa, sendo o instrumento da decisão considerado título executivo para fundamentar a respectiva ação de execução.

Quando o caso fortuito ou força maior, comprovadamente alheio à vontade do gestor responsável, tornar materialmente impossível o julgamento de mérito, as contas poderão ser consideradas lliquidáveis (artigo 20 da Lei no 8.443, de 16 de julho 1992). Neste caso, o TCU ordenará o trancamento das contas que forem consideradas iliquidáveis e o consequente arquivamento do processo.

Exemplos de casos em que as contas são consideradas iliquidáveis abrangem aqueles em que eventos da natureza, tais como inundações, desabamentos etc., ou, ainda, quando incêndios - não provocados pelo gestor responsável - destroem a documentação que possibilitava a comprovação da regular aplicação da verba que lhe foi destinada.

Segundo o artigo 23 da Decisão Normativa TCU no 172, de 12 de dezembro de 2018 , os processos de contas anuais dos IF's serão autuados pelas unidades técnicas no sistema de processo eletrônico do Tribunal em até 
quinze dias após a conclusão dos trabalhos do Ministro da Educação, autoridade supervisora das contas.

A publicação da decisão terminativa do processo de julgamento das contas, acompanhada de seus fundamentos, será por meio de acórdão a ser publicado no Diário Oficial da União, conforme artigos 23 e 29 da Lei ํㅜ 8.443, de 16 de julho 1992.

\section{CONTRIBUIÇÕES PARA O PROCESSO DE ENSINO-APRENDIZAGEM}

Pode parecer deslocado tratar-se de processo de ensino-aprendizagem como práticas permeadas pela ação administrativa, mas isso apenas se nos limitarmos à concepção do senso comum quanto à prestação de contas.

Conforme já fora dito aqui, o conceito de prestação de contas evoluiu, preocupando-se não apenas com conformidades orçamentárias, financeiras e contábeis, mas também com o atingimento de metas, resultados e objetivos propostos.

Na Educação Profissional Tecnológica, a Lei oㅜ 11.892, de 29 de dezembro de 2008 (que institui a Rede Federal de Educação Profissional, Científica e Tecnológica, cria os Institutos Federais de Educação, Ciência e Tecnologia, e dá outras providências) prevê suas características, finalidades e objetivos, tópicos esses a serem analisados ao momento da elaboração e julgamento dos relatórios de gestão dos IF's.

Essa avaliação e controle dos Institutos por meio dos seus respectivos relatórios de gestão permitem a confrontação entre o planejado e o de fato executado no processo educativo, comprovando, assim, seus resultados, por meio da análise de seus indicadores constantes relatórios de gestão dos IF's.

Desse modo, a atuação dos órgãos de controle em relação ao julgamento da prestação de contas do Institutos Federais tem como desiderato último a melhoria na qualidade do ensino de toda a Rede Federal de Educação Profissional Tecnológica, uma vez que uma instituição de educação bem organizada, focada nos meios que busquem a efetivação de sua missão e do seu planejamento estratégico consegue propiciar condições favoráveis às atividades de ensino-aprendizagem desenvolvidas, tendo como exemplo uma melhor alocação de recursos em atividades-fins.

Resta claro que a avaliação valorativa realizada pelos órgãos de controle sobre a prestação de contas dos Institutos Federais, através de seus relatórios de gestão, apresenta-se como meio de melhoria do processo de ensino-aprendizagem à medida que visa garantir as condições mais ideais de funcionamento das Instituições, similarmente ao que preconiza Libâneo e col. (2012). 
Conforme explicita Luck (2014, p. 25), destaca-se o reconhecimento de que é na sala de aula que ocorre a aprendizagem, haja vista que ao professor cabe a responsabilidade direta pelos resultados da aprendizagem de seus alunos. Contudo, a gestão dos IF's é responsável pela efetividade do trabalho dos professores e pela qualidade do ambiente escolar, cabendo aos seus gestores a responsabilidade pelos resultados que os professores promovam, a serem comprovados e avaliados por meio de seus relatórios de gestão.

De outro turno, a publicidade dos relatórios de gestão dos IF's também possibilita à população o conhecimento e a avaliação dos serviços oferecidos, trazendo contribuições na melhoria do processo de ensino-aprendizagem na Educação Profissional Tecnológica haja vista a promoção de uma gestão mais democrática e transparente quanto ao atingimento de suas finalidades.

\section{CONSIDERAÇÕES FINAIS}

A prestação de contas anuais dos Institutos Federais envolve a obrigação social de prestar informações sobre algo que seus gestores são responsáveis, transmitindo transparência e responsabilidade à sociedade.

Nesse sentido, esse estudo buscou demonstrar como ocorre a prestação de contas anuais dos IF's e a atuação dos respectivos órgãos de controle interno e externo nessa atividade, esclarecerendo a forma, os trâmites, os responsáveis e os documentos necessários para efetivação desta obrigação, além de destaca-lá como meio para contribuições na melhoria do processo de ensino-aprendizagem na Educação Profissional e Tecnológica.

Para tanto, introduziu-se os conceitos de controle e prestação de contas ligados ao setor público, assim como se explanou brevemente sobre o controle interno e externo do Poder Executivo Federal, com enfoque nos órgãos que supervisionam os Institutos Federais e suas competências quanto à prestação de contas dessas entidades.

Por fim, ressaltou-se que a atuação dos órgãos de controle no julgamento da prestação de contas dos Institutos Federais tem como desiderato último a melhoria na qualidade de ensino de toda a Rede Federal de Educação Profissional Tecnológica, haja vista suas contribuições na melhoria do processo de ensino-aprendizagem na EPT à medida que garante as condições de funcionamento das Instituições e promove uma gestão mais democrática e transparente quanto ao atingimento de suas finalidades.

Ademais, reconhecem-se as limitações desse estudo quanto ao aferimento do grau da capacidade dessa prestação de contas dos IF's apresentarem uma exitosa accountability, havendo, portanto, a necessidade de aprofundamento da pesquisa através da avaliação da efetiva transparência e 
controle social que se obtém com a realização da prestação de contas anuais pelos Institutos Federais de Educação, Ciência e Tecnologia nos moldes exigidos pelos órgãos de controle.

\section{REFERÊNCIAS}

ARAGÃO JÚNIOR, Milton da Paz. O controle interno da Administração Pública brasileira como instrumento de accountability horizontal sob o enfoque gerencialista. In: Fórum da Rede de Gestão Pública do Piauí REGEPI, 2018. Controle, Transparência e Eficiência, v. 01. p. 54-67, $2018 .$. Disponível em http://www.ppgp.ufpi.br/\#programacao. Acesso em 02 mar. 2019.

\section{BRASIL. [Constituição (1988)]. Constituição da República Federativa do} Brasil de 1988. Brasília, DF: Presidência da República. Disponível em: http://www.planalto.gov.br/ccivil_03/constituicao/constituicaocompilado.htm. Acesso em: 02 mar. 2019.

BRASIL. Decreto no 3.591, de 6 de setembro 2000. Dispõe sobre o Sistema de Controle Interno do Poder Executivo Federal e dá outras providências. Brasília-DF, [2000]. Disponível em: http://www.planalto.gov.br/ccivil_03/decreto/D3591.htm. Acesso em: 02 mar. 2019.

BRASIL. Lei no 8.443, de 16 de julho de 1992. Dispõe sobre a Lei Orgânica do Tribunal de Contas da União e dá outras providências. Brasília-DF, [1992]. Disponível em: http://www.planalto.gov.br/Ccivil_03/leis/L8443.htm. Acesso em: 03 mar 2019.

BRASIL. Lei no 11.892, de 29 de dezembro de 2008. Institui a Rede Federal de Educação Profissional, Científica e Tecnológica, cria os Institutos Federais de Educação, Ciência e Tecnologia, e dá outras providências. Brasília-DF, [2008]. Disponível em: http://www.planalto.gov.br/ccivil_03/_ato20072010/2008/lei/111892.htm. Acesso em: 03 mar 2019.

BRASIL. Tribunal de Contas da União. Decisão Normativa TCU no 170, de 19 de setembro de 2018. Dispõe acerca das unidades cujos dirigentes máximos devem prestar contas de suas gestões ocorridas no exercício de 2018. Brasília-DF, [2018]. Disponível em:

https://portal.tcu.gov.br/contas/contas-e-relatorios-de-gestao/contas-doexercicio-de-2018.htm. Acesso em: 03 mar 2019.

BRASIL. Tribunal de Contas da União. Decisão Normativa TCU no 172, de 12 de dezembro de 2018. Dispõe sobre a relação das unidades prestadoras de contas cujos responsáveis terão as contas de 2018 julgadas pelo Tribunal e especifica conteúdo e condições. Brasília-DF, [2018]. Disponível em: https://portal.tcu.gov.br/contas/contas-e-relatorios-de-gestao/contas-doexercicio-de-2018.htm. Acesso em: 03 mar 2019. 
BRASIL. Tribunal de Contas da União. Instrução Normativa no 63 , de $1^{\circ}$ de setembro de 2010. Estabelece normas de organização e de apresentação dos relatórios de gestão e das peças complementares que constituirão os processos de contas da administração pública federal, para julgamento do Tribunal de Contas da União, nos termos do art. 7º da Lei oㅡ 8.443, de 1992. Brasília-DF, [2010]. Disponível em:

http://www.fazenda.gov.br/assuntos/atuacao-internacional/arquivos/instrucaonormativa-tcu-no-63-de-1o-de-setembro-de-2010.pdf/view. Acesso em: 03 mar 2019.

BRASIL. Tribunal de Contas da União. Portaria no 369, de 17 de dezembro de 2018. Dispõe sobre as orientações para a elaboração do relatório de gestão, rol de responsáveis, demais relatórios, pareceres, declarações e informações suplementares para a prestação de contas referentes ao exercício de 2018, bem como sobre procedimentos para a operacionalização do Sistema de Prestação de Contas (e-Contas), conforme as disposições da Decisão Normativa - TCU 170, de 19 de setembro de 2018. Brasília-DF, [2018]. Disponível em:

https://portal.tcu.gov.br/lumis/portal/file/fileDownload.jsp?fileld=8A81881E67C 853A90167CCF3589F68C4. Acesso em: 03 mar 2019.

BUTA, Bernardo Oliveira; TEIXEIRA, Marco Antônio Carvalho;

SCHURGELIES, Vinicius. Accountability nos atos da administração pública federal brasileira. Pretexto, Belo Horizonte, v. 19, N 4, p. 46-62, outdez, 2018. Disponível em: http://dx.doi.org/10.21714/pretexto.v19i4.5715. Acesso em: 06 mar. 2019.

CASTRO, Domingos Poubel. Auditoria e controle interno na administração pública. 2. ed. São Paulo: Atlas, 2009.

DI PIETRO, Maria Sylvia Zanella. Direito administrativo. 27. ed. São Paulo: Atlas, 2014.

JENSEN, Michael.; MECKLING, William. Teoria da firma: comportamento dos administradores, custos de agência e estrutura de propriedade. Rev. adm. empres., São Paulo, v. 48, n. 2, p. 87-125, jun. 2008. Disponível em http://www.scielo.br/scielo.php?script=sci_arttext\&pid=S0034-

$75902008000200013 \&$ Ing = en\&nrm=iso. Acesso em 06 mar. 2019.

LIBÂNEO, José Carlos; OLIVEIRA, João Ferreira; e TOSCHI, Mirza Seabra.

Educação Escolar: políticas, estrutura e organização. 10. ed. São Paulo: Cortez, 2012.

\section{LUCK, Heloísa. Gestão do Processo de Aprendizagem pelo Professor.}

Série Cadernos de Gestão. Petropólis, RJ: Vozes, 2014.

MEIRELLES, Hely Lopes. Direito administrativo brasileiro. 35. ed. São Paulo: Malheiros, 2009.

SILVA, Flávia de Araujo e; MARIO, Poueri do Carmo. Prestação de contas no setor público: qual é o alcance da difusão dos resultados da organização?. Rev.fac.cienc.econ., Bogotá, v. 24, n. 1, p. 119-133, jan. 2016. Disponível em 
http://www.scielo.org.co/scielo.php?script=sci_arttext\&pid=S0121-

68052016000100009 \&lng=en\&nrm=iso. Acesso em 02 mar. 2019. 